\title{
Mark Stockman, the knight of plasmonics
}

\author{
When the nanophotonics research community finally gets back to in-person conferences, the rooms will have \\ empty chairs on the first row. The chairs will be reserved for Professor Mark I. Stockman.
}

M ark Stockman, one of the founding members and pioneers of plasmonics and nanophotonics, passed away at the age of 73 on 11 November 2020 in Atlanta, Georgia, USA. Always at the front row of the conference hall, nodding in agreement or shaking his head in disapproval, Mark will be remembered not only for his breakthrough studies, but also for his passion for science and the uncompromising standards in research that he applied to himself and others. At every conference session, the speakers would be nervously waiting, with the audience, for Mark's insightful questions.

Mark Stockman was born in Kharkiv, Ukraine, on 21 July 1947. He was descended from a family of military cantonists. The term was applied to Jewish boys who were drafted to military service at the age of twelve and placed for their six-year military education in cantonist schools. The official policy was to encourage their conversion to the state religion of Orthodox Christianity and Jewish boys were coerced to baptism. Mark believed that his ancestor was among a few who escaped conversion and was proud of his Jewish extraction. As a symbol of his origin, Mark treasured an old daguerreotype image of his granddad Gregory Ilich Stockman, a boy with a book in a gymnasium uniform standing next to his mother, who was the wife of the original cantonist.

Mark Stockman read physics at the Kiev State University in Ukraine and the University of Novosibirsk in Russia, where he obtained his MSc in 1970. He then studied under the guidance of Professor Spartak Belyaev and Vladimir Zelevinsky at the Institute of Nuclear Physics, Russian Academy of Sciences, in Novosibirsk, Russia, and received his $\mathrm{PhD}$ in 1974. In 1989, he obtained a Doctor of Science in physics from the Institute of Automation and Electrometry, Russian Academy of Sciences, where he worked until 1989 on nonlinear optics and laser biophysics. While he was a PhD candidate Mark met and married Bronislava (Slava) Mezger, a junior research scientist in biomedicine, and in 1978 they had a son, Dmitry.

In 1990 Mark Stockman moved to the United States to take a research position at the State University of New York at

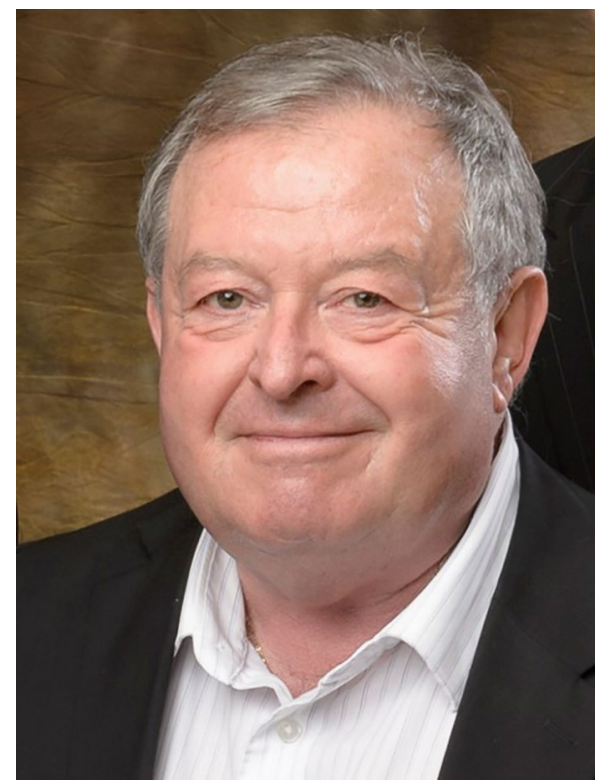

Mark Stockman on 19 November 2014, at a Purdue University Excellence in Research Awards Dinner. Credit: John Underwood/Purdue University

Buffalo, and then in 1991 he took a visiting professorial post at the Washington State University. Mark was appointed professor at the Department of Physics and Astronomy at Georgia State University in 2001, where he became the founding director of the Center for Nano Optics in 2012 and worked until his last days. Mark travelled widely and accepted guest professorial positions at the Max Plank Institute for Quantum Optics in Garching bei München, the University of Stuttgart, Ecole Normale Supérieure de Cachan and Ecole Supérieure de Physique et de Chimie Industrielle in Paris. He was elected a Fellow of the American Physical Society, Optical Society of America and the International Society for Optical Engineering. He received numerous grants and contracts during his career, including those from the US Departments of Defense and Energy.

The theoretical prediction by Stockman and Bergman of the spaser device (surface plasmon amplification by stimulated emission of radiation), a plasmonic version of the laser ${ }^{1}$, was one of the key discoveries in the field of plasmonics that inspired 2,000 citations and massive follow-up experimental research. This paper took one of the first steps towards quantum plasmonics, dealing with surface plasmon fields of a nanosystem, their quantization and stimulated emission. It demonstrated that spasers can generate temporally coherent high-intensity fields of selected surface plasmon modes that can be strongly localized at the nanoscale, including dark modes that do not couple to far-zone electromagnetic fields. From his earlier works on random media and fractals, Mark became interested in generation manipulation of light at the nanoscale, including the generation of plasmon-polaritons by free-electron impact. He introduced plasmonic concentrators based on a self-similar linear chain of several metal nanospheres ${ }^{2}$ and adiabatic taper $^{3}$, where Mark predicted theoretically that surface plasmon-polaritons propagating toward the tip of a tapered plasmonic waveguide are slowed down and asymptotically stopped when they tend to the tip, never actually reaching it. This phenomenon, now widely used in plasmonic research, causes accumulation of energy and giant local fields at the tip and has numerous applications in nanophotonics and nanotechnology. Mark's studies on ultrafast photonics, including ultrafast active plasmonics and attosecond metrology, has provided access to several hitherto immeasurably fast electron phenomena in atoms, molecules and solids ${ }^{4}$. Regardless of the personalities involved, Mark was happy to challenge scientific concepts he did not agree with ${ }^{5,6}$, and keenly defended and promoted his own ideas of the spaser $^{1}$, plasmonic taper ${ }^{3}$ and the ultrafast topological all-optical gate ${ }^{7}$ (one of his last papers), which he passionately believed can change technology. He earned the reputation of a theorist with a background, opinion and ideas spanning a very wide range of subjects, from solid state physics to biomedicine.

"I had a good life" - this was one of the last things Mark told his friends. Not only did he have a vibrant, eventful life full of accomplishments and joy (his favourite hobby was skiing), but he also shared it with all of us. Mark Stockman, exceptional scientist and personality, will be dearly missed by his wife Slava, son 
Dmitry, friends and the nanophotonics community.

Alexandra Boltasseva (D) 1⿴,

Vladimir M. Shalaev $\mathbb{D}^{1}$ and

Nikolay. I. Zheludev 2,3

${ }^{1}$ School of Electrical and Computer

Engineering, Purdue University, West Lafayette,
IN, USA. ${ }^{2}$ Optoelectronics Research Centre,

$\square$ University of Southampton, Southampton, UK. ${ }^{3}$ Nanyang Technological University, Singapore, Singapore.

$凶_{e-m a i l: a e b @ p u r d u e . e d u}$

Published online: 7 April 2021

https://doi.org/10.1038/s41566-021-00799-7
References

1. Bergman, D. J. \& Stockman, M. I. Phys. Rev. Lett. 90, 027402 (2003).

2. Li, K., Stockman, M. I. \& Bergman, D. J. Phys. Rev. Lett. 91 , 227402 (2003).

3. Stockman, M. I. Phys. Rev. Lett. 93, 137404 (2004).

4. Krausz, F. \& Stockman, M. I. Nat. Photon. 8, 205-213 (2014).

5. Stockman, M. I. Phys. Rev. Lett. 98, 177404 (2007).

6. Javani, M. H. \& Stockman, M. I. Phys. Rev. Lett. 117, 107404 (2016).

7. Nematollahi, F. et al. Phys. Rev. B 102, 125413 (2020). 